\title{
STUDI ETNOMATEMATIKA: EKSPLORASI KONSEP-KONSEP TEOREMA PYTHAGORAS PADA BUDAYA BANTEN
}

\author{
Dinar Nirmalasari ${ }^{1}$, Pinta Deniyanti Sampoerno², Makmuri ${ }^{3}$ \\ 1,2,3 Universitas Negeri Jakarta, Program Studi Magister Pendidikan Matematika, Jakarta-Indonesia \\ E-mail: 1ndinar27@gmail.com
}

\begin{abstract}
This study links the concept of Pythagoras to Banten culture. Banten culture has ethnomathematical elements, especially the Pythagorean concept. The concept of Pythagoras in Banten culture includes the construction of buildings or sizes that have Pythagorean rules. The search for mathematical order in Banten culture can be a study that can be integrated into the learning of mathematics in the material of the Pythagorean Theorem. The purpose of this study explores Banten culture, namely the roof of the baduy traditional house, batik leuit cikadu pandeglang motif, banten arch, kasunyatan mosque arch, baduy totopong, baduy weaving thread, and the roof of the great mosque of Banten against the Pythagorean concept. Research methods use ethnographic approaches by integrating theoretical and empirical studies derived from observation and interview activities as data gathering tools. The results showed that Banten culture has various Pythagorean concepts, namely the concept of the Pythagorean theorem in the right triangle, the Pythagorean theorem, determine the type of triangle based on the known side, the Pythagorean triple, the ratio of the sides on the equilateral right triangle. The ratio of the sides of the right triangle with angles of $30^{\circ}, 60^{\circ}$, and $90^{\circ}$. With ethnomathematical study of Banten culture as a form of strengthening character education on nationalist values by having the competence of love attitudes towards their own culture can grow and be owned by students as the identity of the nation.
\end{abstract}

Keywords: Banten culture, ethnomathematics, pythagoras

\begin{abstract}
ABSTRAK
Penelitian ini mengaitkan konsep Pythagoras dengan Budaya Banten. Budaya Banten memiliki unsur etnomatematika terutama konsep Pythagoras. Konsep Pythagoras dalam budaya Banten meliputi konstruksi bangunan atau ukuran yang memiliki aturan Pythagoras. Penelusuran keteraturan matematis pada budaya Banten dapat menjadi kajian yang dapat diintegrasikan dalam pembelajaran matematika pada materi Teorema Pythagoras. Tujuan penelitian ini mengeksplorasi budaya Banten yaitu atap rumah adat baduy, motif batik leuit cikadu pandeglang, gapura khas banten, gapura masjid kasunyatan, totopong baduy, ulur tenun baduy, dan atap Masjid Agung Banten terhadap konsep Pythagoras. Metode penelitian menggunakan pendekatan etnografi dengan mengintegrasikan kajian teoritis dan empiris yang diperoleh dari kegiatan observasi dan wawancara sebagai alat pengumpul data. Hasil penelitian menunjukan bahwa kebudayaan Banten memiliki berbagai konsep Pythagoras yaitu konsep Teorema Pythagoras pada segitiga siku-siku, Teorema Pythagoras, menentukan jenis segitiga berdasarkan sisi yang diketahui, triple Pythagoras, perbandingan sisi-sisi pada segitiga sikusiku sama kaki. Perbandingan sisi-sisi pada segitiga siku-siku dengan sudut $30^{\circ}, 60^{\circ}$, dan $90^{\circ}$. Dengan kajian etnomatematika terhadap budaya Banten sebagai bentuk penguatan pendidikan karakter pada nilai nasionalis dengan memiliki kompetensi sikap kecintaan terhadap budayanya sendiri dapat tumbuh dan dimiliki oleh siswa sebagai jati diri bangsa.
\end{abstract}

Kata kunci: Budaya Banten, matematika, pythagoras

Dikirim: 14 Juni 2021; Diterima: 04 September 2021; Dipublikasikan: 30 September 2021

Cara sitasi: Nirmalasari, D., Sampoerno, P. D., \& Makmuri. (2021). Bilangan kromatik lokasi pada graf total dan graf splitting dari graf bintang. Teorema: Teori dan Riset Matematika, 6(2), 161-172. DOl: http://dx.doi.org/10.25157/teorema.v6i2.5472 


\section{PENDAHULUAN}

Etnomatematika adalah berbagai kegiatan matematika yang berkembang atau dimiliki oleh masyarakat, meliputi konsep-konsep matematika seperti dalam warisan budaya dari sebuah kuil, tembikar, prasasti, satuan lokal, peralatan tradisional, permainan tradisional, kain batik dan desain bordir, serta pola pemukiman (Lestari et al., 2019). Mempelajari matematika dengan memasukkan etnomatematika dapat menambah pengetahuan dan wawasan mengenai adanya keberadaan matematika pada unsur budaya yang dimiliki, meningkatkan pemikiran matematis, dan dapat memfasilitasi dalam mengaitkan konsepkonsep yang dipelajari dalam situasi dunia nyata (Noto et al., 2018).

Pendidikan merupakan salah satu sektor pembangunan nasional yang didalamnya terdapat upaya mencerdaskan kehidupan bangsa untuk menghasilkan manusia yang berkualitas dan berwawasan luas. Adapun budaya atau kebudayaan dapat diartikan sebagai hasil kegiatan dari penciptaan akal budi, pikiran, dan adat istiadat manusia (Khaerunnisa et al., 2018).

Etnomatematika hadir melalui persepsi yang berusaha menemukan keterkaitan budaya dengan konsep matematika tertentu. Etnomatematika sebagai produk pemikiran bahwa matematika berasal dari budaya. Kajian budaya meliputi berbagai unsur yaitu tradisi, bangunan, tutur bahasa dan gaya arsitektur. Menelaah etnomatematika dapat disebut pula sebagai pendidikan matematika berbasis budaya daerah. Hal ini cocok guna mengajarkan siswa untuk lebih mencintai budaya.

Pendidikan dan budaya merupakan dua hal yang tidak dapat dipisahkan dan sesuatu hal yang tidak bisa dihindari dalam kehidupan sehari-hari. Hubungan pendidikan dan budaya tercermin dari kebutuhan mendasar bagi setiap individu dan masyarakat serta budaya merupakan suatu kesatuan yang utuh dan menyeluruh yang berlaku dalam suatu masyarakat. Budaya dapat memberikan pendidikan kepada setiap individu dalam mempelajari suatu disiplin ilmu.

Wujud kebudayaan menurut Khaerunnisa et al., (2018) dibedakan menjadi tiga bagian, yaitu: (1) Gagasan, kebudayaan yang berbentuk kumpulan ide-ide atau gagasan bersifat abstrak dan tidak dapat disentuh atau diraba; (2) Aktivitas, kebudayaan dengan bentuk sebuah tindakan berpola dari manusia dalam bermasyarakat; dan (3) Artefak, kebudayaan dengan wujud fisik berupa hasil karya atau penciptaan manusia berupa benda-benda yang konkret dan dapat diraba.

Banten adalah salah satu wilayah yang memiliki keanekaragaman budaya yang masih berkembang sampai saat ini misalnya dalam kesenian adat istiadat, rumah adat, makanan khas, pakaian adat, dan lain sebagainya. Potensi budaya yang ada di Banten harus digali secara optimal dikarenakan kebudayaan Banten memiliki keunikan dan kekhasannya tersendiri. Keunikan tersebut dapat menajdi sebuah modal bagi eksistensi budaya Banten untuk diperkenalkan kepada masyarakat umum.

Pada masa lalu di Banten terdapat kesultanan yang bernama kesultanan Banten. Setelah kesultanan Banten berakhir, yang tersisa saat ini adalah peninggalan sejarah berupa bekas istana kerajaan, Masjid Agung Banten, benteng Speelwijk, Masjid Kasunyatan, dan lain sebagainya. Bangunan-bangunan bersejarah ini termasuk suatu kategori kebudayaan dari jenis artefak yang memiliki dasar konsep-konsep matematika (Anggraheni et al., 2020).

Pada wilayah Banten juga terdapat sebuah komunitas yang masih memegang teguh tradisi warisan nenek moyangnya yaitu Suku Baduy. Menurut Sutoto (2017) Baduy atau orang kanekes adalah suatu kelompok masyarakat adat Sunda di Wilayah Kabupaten Lebak, Banten. Suku Baduy memiliki beberapa jenis kebudayaan, di antaranya yaitu rumah adat Baduy (Susilowati et al., 2020), totopong Baduy (Heriawan et al., 2018), motif batik Baduy, ulur tenun Baduy (Megantari \& Setyawan, 2019), leuit Baduy (Iskandar \& Iskandar, 2017), dan lain-lain.

Benda-benda seperti atap rumah adat Baduy, motif batik khas Banten, gapura khas Banten, gapura masjid Kasunyatan, totopong Baduy, alas menara Banten, ulur tenun Baduy, atap masjid agung Banten, dan leuit Baduy mengandung berbagai konsep matematika dalam materi teorema Pythagoras. Teorema Pythagoras adalah suatu teorema yang menyatakan pada setiap segitiga siku-siku berlaku jumlah kuadrat panjang sisi-sisi siku-sikunya sama dengan kuadrat panjang sisi miring (Cahyanindya \& Mampouw, 2020).

Pemahaman siswa terhadap konsep teorema Pythagoras merupakan hal yang penting dikarenakan teorema Pythagoras merupakan salah satu materi prasyarat untuk belajar materi lainnya 
seperti materi segitiga siku-siku, bangun ruang sisi lengkung, lingkaran, garis singgung lingkaran, dan lainlain (Cahyanindya \& Mampouw, 2020). Titasari et al., (2019) menambahkan bahwa kemampuan pemahaman matematis penting untuk dimiliki oleh siswa dikarenakan kemampuan tersebut merupakan prasyarat seseorang untuk memiliki kemampuan yang lainnya dengan kata lain kemampuan pemahaman matematis merupakan dasar dari kemampuan-kemampuan yang lain, ketika seseorang belajar matematika agar mampu memahami konsep, maka saat itulah orang tersebut mulai merintis kemampuan-kemampuan berpikir matematis yang lainnya. Berdasarkan hasil wawancara yang dilakukan terhadap siswa di beberapa SMP Kota Serang, hal-hal yang menyebabkan teorema Pythagoras menjadi sulit dipahami salah satunya yaitu learning ontogenical obstacle (kurangnya minat serta motivasi siswa dalam mempelajari materi teorema Pythagoras). Pemahaman ada relasi kuat dengan semangat belajar siswa. Hal ini merujuk pada situasi bahwa dengan bertambahnya satuan motivasi belajar selanjutnya kemampuan pemahaman siswa turut akan terjadi penambahan (Akbar et al., 2017).

Berdasarkan penelitian yang dilakukan oleh Titasari et al., (2019) bahwa kemampuan pemahaman matematis siswa yanng menggunakan pendekatan Problem Based Learning lebih baik dibandingkan dengan yang menggunakan pembelajaran biasa, dikarenakan pembelajaran yang menggunakan pendekatan Problem Based Learning dalam proses belajar di dalamnya melibatkan siswa untuk berusaha memecahkan masalah yang terkait dunia nyata. Penelitian yang dilakukan oleh Rahmawati (2020) diperoleh hasil pemahaman konsep siswa di Minangkabau terkait materi teorema Pythagoras menjadi lebih baik dikarenakan pembelajaran yang menggunakan pendekatan etnomatematika pada rumah gadang Minangkabau. Hal tersebut terjadi karena pembelajaran menjadi bermakna dengan memetakan konteks kehidupan sekeliling siswa atau konteks budaya yang telah para siswa kenal sebelumnya sehingga menjadi sesuatu yang konkret dan bermakna dibenak siswa. Sitohang et al., (2020) dalam penelitiannya mengatakan bahwa kemampuan berpikir kreatif matematis siswa menjadi lebih baik pada topik teorema Pythagoras setelah menggunakan model pembelajaran kontekstual dikarenakan pembelajaran kontekstual membantu guru mengaitkan konten mata pelajaran dalam situasi dunia nyata dan mengajak siswa menciptakan hubungan antara pengetahuan dan aplikasinya di kehidupan sehari-hari serta membantu siswa untuk dapat menyerap pemahaman konsep teorema Pythagoras menjadi lebih baik karena memiliki pengalaman belajar terkait lingkungannya sendiri. Matematika adalah sarana untuk menemukan hubungan suatu pola, mengembangkan kreativitas, dan meningkatkan kesadaran budaya (Nugroho \& Riyanto, 2019).

Berdasarkan penelitian-penelitian di atas, untuk menanamkan pemahaman konsep teorema Pythagoras disinyalir akan lebih mudah dipahami jika dalam mempelajarinya menggunakan permasalahan dunia nyata dan pengalaman bermakna yang berasal dari kehidupan sehari-hari salah satunya yaitu budaya. Sehingga dalam mempelajari matematika perlu mengkaitkan antara budaya dengan matematika, keterkaitan antara matematika dengan budaya adalah etnomatematika.

\section{METODE PENELITIAN}

Penelitian ini termasuk ke dalam penelitian kualitatif berdesain etnografi. Penelitian diawali dengan menganalisis dokumen-dokumen yang ada di Balai Pelestarian Cagar Budaya Banten. Dalam penelitian ini menggunakan situasi sosial (tempat, pelaku, dan aktivitas) dan narasumber. Peneliti melakukan observasi ke lokasi dan wawancara kepada orang-orang yang dipandang tahu tentang budaya-budaya yang ada di lokasi setempat.

Observasi dilakukan pada obyek penelitian diantaranya yaitu atap rumah adat Baduy, motif batik Cikadu Pandeglang, gapura khas Banten, menara pengintai Benteng Speelwijk, gapura masjid Kasunyatan, totopong Baduy, alas menara Banten, ulur tenun Baduy, atap masjid agung Banten, dan leuit Baduy yang mengandung konsep-konsep teorema Pythagoras. Selanjutnya, wawancara dilakukan kepada orang-orang setempat yang dipandang tahu tentang budaya-budaya yang ada di beberapa lokasi obyek penelitian.

Teknik analisis data yang digunakan dalam penelitin ini adalah triangulasi yaitu reduksi data, penyajian data, dan penarikan kesimpulan. Cagar budaya dan bangunan budaya Banten didokumentasikan untuk ditelaah konstruksinya dengan konsep pythagoras. Reduksi data untuk memilih bagian dari bangunan budaya yang akan dianalisis. Hasil reduksi kemudian diperkuat dengan wawancara dan observasi untuk 
mengonfirmasi konsep phytagoras. Tahapan selanjutnya yaitu penyajian data yang disajikan dengan menampilkan gambar beberapa budaya Banten yang dilengkapi dengan penjelasan konsep teorema Pytahgoras yang terkandung di dalamnya. Setelah itu dilakukan penarikan kesimpulan untuk mengetahui berbagai konsep-konsep matematika yang terdapat pada beberapa kebudayaan Banten.

\section{HASIL DAN PEMBAHASAN}

1. Konsep Teorema Pythagoras pada Segitiga Siku-Siku Atap Rumah Adat Baduy

Rumah adat Baduy disebut imah, berbentuk empat persegi panjang dengan atap kampung dan sosoran di salah satu sisinya yang disebut atap sulah nyanda (Megantari \& Setyawan, 2019).

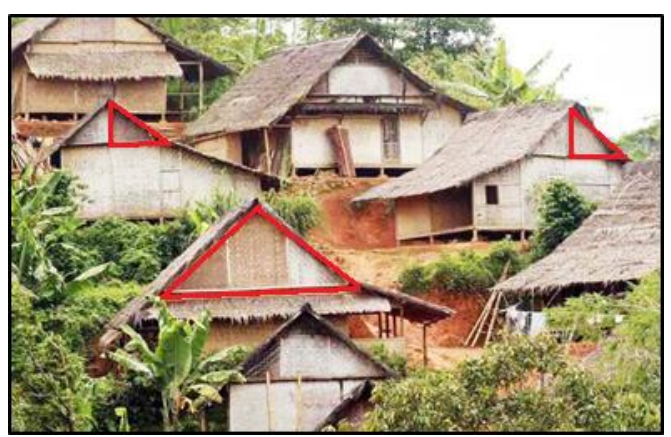

Gambar 1. Atap rumah adat Baduy

Bagian dalam rumah terdiri dari tiga ruangan, yakni (1) Sosoro di sisi selatan yang digunakan untuk menerima tamu; (2) Tepas di sisi samping memanjang ke belakang dan digunakan untuk ruang kegiatan keluarga; dan (3) Imah yang merupakan inti rumah digunakan untuk kegiatan inti keluarga (Sardjono \& Nugroho, 2017).

Pada bagian atap rumah adat Baduy berbentuk segitiga siku-siku, berdasarkan pengukuran yang dilakukan secara langsung di lokasi, didapatkan data bahwa panjang masingmasing sisinya yaitu 2,9 meter, 2,1 meter, dan 2 meter. Berdasarkan konsep teorema Pythagoras diuraikan sebagai berikut.

$$
c^{2}=a^{2}+b^{2}
$$

(Agarwal, 2020).

Sisi tegak pertama $=a=2,1$ meter

Sisi tegak lainnya $=b=2$ meter

Sisi terpanjang $=$ sisi miring $=c=2,9$ meter

Selanjutnya dilakukan perhitungan sebagai berikut

$$
\begin{aligned}
(2,9)^{2} & =(2,1)^{2}+(2)^{2} \\
(8,41) & =(4,41)+(4) \\
8,41 & =8,41
\end{aligned}
$$

Berdasarkan perhitungan di atas maka atap rumah adat Baduy mengandung konsep teorema Pythagoras. Melalui bentuk ini, siswa dapat belajar tentang konsep teorema Pytahgoras pada segitiga siku-siku. Siswa dapat menghitung panjang-panjang sisi-sisi pada segitiga sikusiku menggunakan konsep teorema Pythagoras. Kemampuan ini penting untuk dimiliki siswa karena matematika adalah pemecahan masalah yang seharusnya dikaitkan dengan masalah sehari-hari.

2. Pembuktian Teorema Pythagoras Motif Batik Leuit Cikadu Pandeglang

Motif batik Leuit diambil dari salah satu tempat yang digunakan sebagai tempat penyimpanan padi setelah panen atau lumbung padi. Leuit atau lumbung adalah bangunan 
tradisional yang diperuntukan untuk menyimpan padi hasil pertanian. Leuit terdapat pada kebudayaan masyarakat agraris masyarakat Banten (Saepudin, 2019).

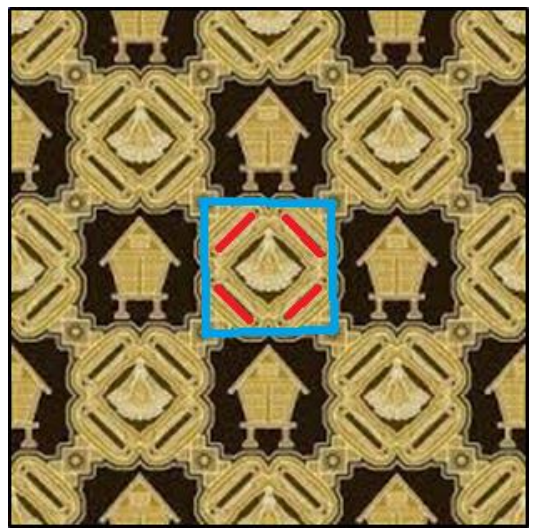

Gambar 2. Motif batik Cikadu Pandeglang

Pada motif batik di atas terdapat motif yang berbentuk perpotongan persegi dan segitiga yang mengandung konsep pembuktian teorema Pythagoras.

a

b

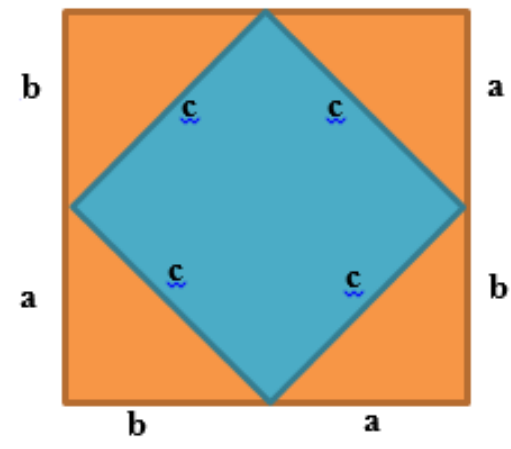

Gambar 3. Persegi potong

$$
\begin{aligned}
\text { Luas persegi orange } & =\text { Luas persegi biru + Luas } 4 \text { segitiga } \\
(a+b)^{2} & =c^{2}+(4 \text {. luas segitiga }) \\
a^{2}+2 a b+b^{2} & =c^{2}+\left(4 \cdot \frac{1}{2} a \cdot b\right) \\
a^{2}+2 a b+b^{2} & =c^{2}+2 a b \\
a^{2}+2 a b-2 a b+b^{2} & =c^{2}+2 a b-2 a b \\
a^{2}+b^{2} & =c^{2}
\end{aligned}
$$

3. Menentukan Jenis Segitiga berdasarkan Sisi yang diketahui Gapura Khas Banten

Gapura khas Banten adalah gapura Keraton Kaibon dengan kontruksi bangunannya berasal dari bahan bata batu yang disejajarkan yang dilapisi pasir dan semen. Pembuatan gapura ini selalu diberi pondasi pendek dengan macam pondasi menerus yang ditumpuk di bawah dinding gapura dengan perbandingan lebar pondasi yang sama besar dan terletak pada kedalaman yang sama (Khaerunnisa et al., 2018). 
Pada gapura khas Banten di bagian atasnya membentuk sebuah segitiga. Berdasarkan pengukuran yang dilakukan secara langsung di lokasi, didapatkan data bahwa besar sudutnya adalah $90^{\circ}$, panjang sisi tegak pertama adalah $140 \mathrm{~cm}$, panjang sisi tegak lainnya adalah $105 \mathrm{~cm}$ dan panjang sisi miringnya adalah $175 \mathrm{~cm}$. Selanjutnya dilakukan perhitungan sebagai berikut.

$$
\begin{aligned}
& a=\text { sisi tegak pertama } \\
& b=\text { sisi tegak lainnya } \\
& c=\text { sisi miring }
\end{aligned}
$$

$$
\begin{aligned}
(175)^{2} & =(140)^{2}+(105)^{2} \\
(30.625) & =(19.600)+(11.025) \\
30.625 & =30.625 \\
c^{2} & =a^{2}+b^{2}
\end{aligned}
$$

Berdasarkan perhitungan di atas segitiga Gapura Khas Banten merupakan segitiga siku-siku, maka berlaku: $c^{2}=a^{2}+b^{2}$. Kesimpulannya adalah jika $c^{2}=a^{2}+b^{2}$, maka segitiga tersebut merupakan segitiga siku-siku.

\section{Gapura Masjid Kasunyatan}

Masjid Kasunyatan berdiri sekitar 1552-1570 M dan berlokasi di Desa Kasunyatan, Kecamatan Kasemen, Kota Serang. Masjid tersebut awalnya disebut sebagai Masjid AI-Fatihah yang artinya "pembuka". Pembuka mengandung arti sebagai simbol pembuka untuk proses penyebaran dan pengajaran agama Islam di Banten. Kasunyatan memiliki arti kesucian, kenyataan, kesunyian, dan kesepian (Saefullah, 2018).

Masjid Kasunyatan mempunyai 3 sisi gapura yang berposisi di sebelah barat, timur, dan selatan. Gapura di arah barat disebut pintu masuk ke arah halaman makam di sisi utara dan juga berfungsi pembatas dengan makam di halaman timur. Pada bagian atasnya terdapat ragam hias pola geometris. Pintu masuk berukuran tinggi sekitar 2,10 meter dan lebar sekitar 1,25 meter untuk bagian atas berpola melengkung (Nadya, 2017).

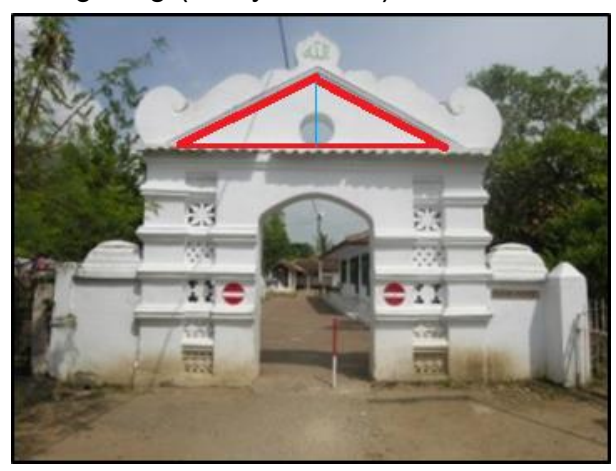

Gambar 4. Gapura Masjid Kasunyatan

Pada gapura Masjid Kasunyatan di bagian atasnya ada ornamen yang berbentuk sebuah segitiga. Berdasarkan pengukuran yang dilakukan secara langsung di lokasi, didapatkan data bahwa besar sudutnya adalah $120^{\circ}$, panjang sisi tegak pertama adalah $280 \mathrm{~cm}$, panjang sisi tegak lainnya adalah $280 \mathrm{~cm}$ dan panjang sisi miringnya adalah $463 \mathrm{~cm}$. Selanjutnya dilakukan perhitungan sebagai berikut.

$$
\begin{aligned}
& a=\text { sisi tegak pertama } \\
& b=\text { sisi tegak lainnya } \\
& c=\text { sisi miring }
\end{aligned}
$$$$
\begin{aligned}
(463)^{2} & >(280)^{2}+(280)^{2} \\
(214.369) & >(78.400)+(78.400) \\
214.369 & >156.800 \\
c^{2} & >a^{2}+b^{2}
\end{aligned}
$$

Berdasarkan perhitungan di atas ornamen pada gapura Masjid Kasunyatan merupakan segitiga tumpul, maka berlaku: $c^{2}>a^{2}+b^{2}$. Kesimpulannya adalah jika $c^{2}>a^{2}+b^{2}$, maka segitiga tersebut merupakan segitiga tumpul. 


\section{Triple Pythagoras}

Totopong Baduy

Totopong adalah ikat kepala pria dari Baduy yang memiliki motif batik khas Baduy. Totopong adalah sebuah kain persegi berukuran $50 \times 50 \mathrm{~cm}$ yang kemudian diikatkan ke kepala. Totopong Baduy berfungsi sebagai penutup rambut orang Baduy yang panjang. Totopong memiliki berbagai variasi sesuai dengan teknik ikatnya, seperti parengkos nangka. Parengkos nangka adalah bentuk simple yang melipat kain batik Baduy menjadi segitiga di atas dahi dengan ikatan di bagian belakang kepala (Heriawan et al., 2018).

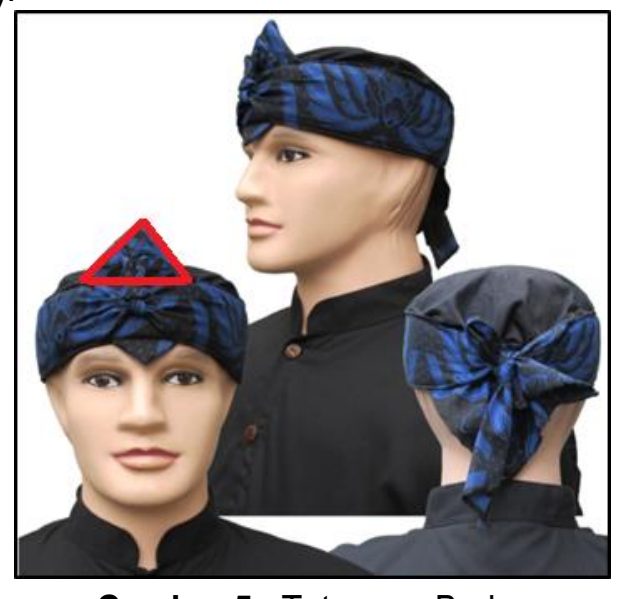

Gambar 5. Totopong Baduy

Pada totopong Baduy ada bagian depan yang membentuk sebuah segitiga. Berdasarkan pengukuran yang dilakukan secara langsung di lokasi, didapatkan data bahwa panjang sisi tegak pertama dan sisi terpendek adalah $6 \mathrm{~cm}$, sisi tegak lainnya adalah $8 \mathrm{~cm}$, dan sisi miringnya adalah $10 \mathrm{~cm}$. Selanjutnya dilakukan perhitungan sebagai berikut.

Totopong baduy yang memiliki ciri segitiga di bagian depan mencirikan karakteristik status sosial yang biasa digunakan dari kalangan kaum pria. Pada konteks matematika segitiga mencirikan konsep Pythagoras. Selain itu kain dan teknik anyam akan mempengaruhi bentuk segitiga. Totopong baduy memiliki keunikan baik segi budaya maupun matematikanya.

Untuk memeriksa tripel Pythagoras yang memiliki FPB dari ketiga sisi segitiga $>1$ dapat menggunakan rumus:

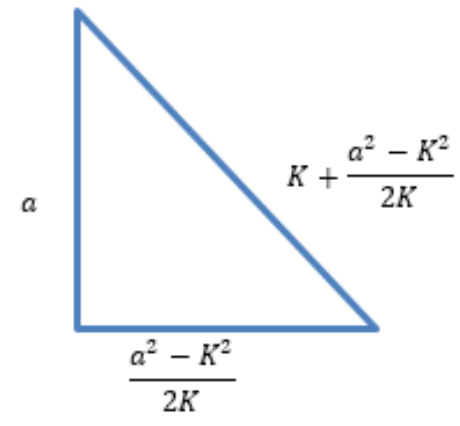

Keterangan: $a$ adalah sisi terpendek dan $K$ adalah FPB dari $(a, b, c)$ (Affaf, 2016)

Gambar 6. Rumus tripel Pythagoras yang memiliki FPB dari ketiga sisi segitiga $>1$ 
Setelah diketahui bahwa FPB dari $(6,8$, dan 10) yaitu 2 , dimana $2>1$ maka berlaku:

$$
\begin{aligned}
a & =6 \mathrm{~cm} \\
\frac{a^{2}-K^{2}}{2 K} & =\frac{6^{2}-2^{2}}{2 \times 2} \\
& =\frac{36-4}{4} \\
& =\frac{32}{4} \\
& =8 \mathrm{~cm} \\
K+\frac{a^{2}-K^{2}}{2 K} & =2+8 \\
& =10 \mathrm{~cm}
\end{aligned}
$$

Berdasarkan perhitungan di atas dapat di tarik kesimpulan bahwa segitiga pada totopong Baduy memiliki sisi-sisi yang merupakan tripel Pythagoras.

\section{Perbandingan Sisi-Sisi pada Segitiga Siku-Siku Sama Kaki}

Ulur Tenun Baduy

Kincir adalah alat ukur yang terbuat dari bahan kayu dan bambu berbentuk bulat atau persegi dimana disekat seperti tangkai payung yang ada jeruji-jerujinya (Maftukha et al., 2017).

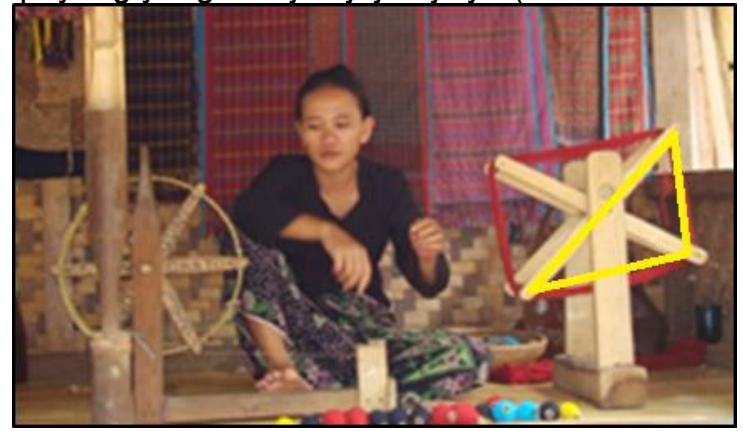

Gambar 6. Ulur Tenun Baduy

Alat ini berfungsi untuk mengulur benang yang sebelumnya ditempatkan pada tenggok dimaksudkan agar benang yang sudah disikat tidak kotor dan cara penggunaannya yaitu bagian ujung benang dicantelkan pada bagian salah satu jeruji kemudian digerakkan memutar, maka benang yang ada ikut berputar dan berada dalam lilitan jeruji, sehingga terbentuklah suatu lingkaran (Maftukha, 2012). Dalam proses menyambungkan antar ujung benar disebut nguluran (Maftukha et al., 2017). Kegiatan ini berupa gerakan menyilang terus menerus dari kisi menuju pajal. Alat tenun ini juga membuat indah kain yang bernilai jual fantastis.

Pada alat tenun Baduy terdiri dari beberapa peralatan salah satunya yaitu alat untuk menyanggah benang yang disebut ulur benang yang membentuk 4 segitiga siku-siku sama kaki. Berdasarkan pengukuran yang dilakukan secara langsung di lokasi, didapatkan data bahwa panjang sisi tegak pertama adalah $10 \mathrm{~cm}$, sisi tegak lainnya adalah $10 \mathrm{~cm}$, dan sisi miringnya adalah 14,14 $\mathrm{cm}$. Selanjutnya dilakukan perhitungan sebagai berikut.

Berdasarkan rumus teorema Pythagoras yaitu $c^{2}=a^{2}+b^{2}$. Selanjutnya analisis perhitungan segitiga siku-siku sama kaki di atas, maka diperoleh:

$$
\begin{aligned}
& c^{2}=a^{2}+b^{2} \\
& c=\sqrt{a^{2}+b^{2}}
\end{aligned}
$$


Jika diketahui $\mathrm{a}=\mathrm{b}$, maka didapatkan:

$$
\begin{aligned}
& c=\sqrt{a^{2}+a^{2}} \\
& c=\sqrt{2 a^{2}} \\
& c=\sqrt{2} \times \sqrt{a^{2}} \\
& c=a \sqrt{2}
\end{aligned}
$$
dan $\sqrt{2}$.

Selanjutnya didapatkan perbandingan sisi-sisi pada segitiga siku-siku sama kaki yaitu 1, 1 ,

6. Perbandingan Sisi-sisi pada Segitiga Siku-siku dengan Sudut $30^{\circ}, 60^{\circ}$, dan $90^{\circ}$

Atap Masjid Agung Banten

Masjid Agung Banten merupakan salah satu masjid tertua yang ada di Indonesia. Dibangun pertama kali oleh Sultan Maulana Hasanuddin pada tahun 1552-1570 M (Naredi et al., 2020). Masjid ini berlokasi di Desa Banten, Kecamatan Kasemen, Kota Serang Provinsi Banten. Masjid tersebut memiliki luas area sekitar 1,3 HA (Laksmi, 2017).

Masjid Agung Banten memiliki atap lima tingkat berbentuk bujur sangkar setinggi $30 \mathrm{~m}$, berupa atap tumpang yang tersusun semakin ke atas makin mengecil (Anggraheni et al., 2020) dan yang paling atas berbentuk limas yang disebut kubah dan setiap sisinya berbentuk segitiga sama sisi (Khaerunnisa et al., 2018). Atap ini menggunakan genteng dengan memolo pada puncaknya, dimana tinggi memolo tersebut adalah 1,2 meter terbuat dari tanah liat. Rancangan atap masjid yang bersusun lima mirip dengan pagoda cina dan menjadi keunikan tersendiri bagi masjid (Anggraheni et al., 2020).

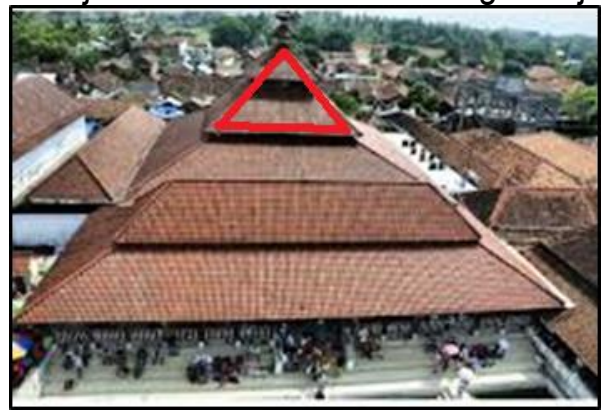

Gambar 7. Atap Masjid Agung Banten

Pada atap Masjid Agung Banten terdiri dari 5 tingkatan. Atap tingkat ketiga membentuk sebuah segitiga sama sisi. Berdasarkan wawancara yang dilakukan secara langsung kepada pengurus Masjid Agung Banten, didapatkan data bahwa panjang masing-masing ketiga sisinya adalah $120 \mathrm{~cm}$. Selanjutnya dilakukan perhitungan sebagai berikut.

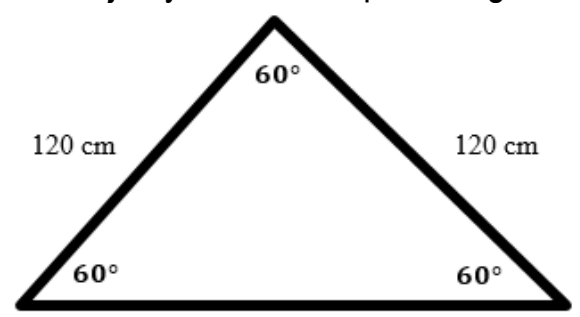

$120 \mathrm{~cm}$

Selanjutnya segitiga di atas dibagi menjadi dua bagian sehingga menjadi

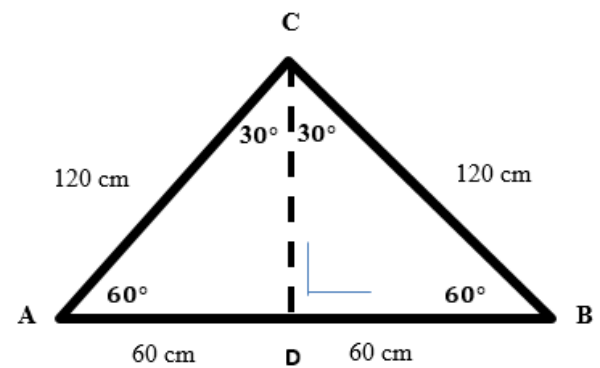

Sehingga jika diambil setengah bagian menjadi gambar di bawah 


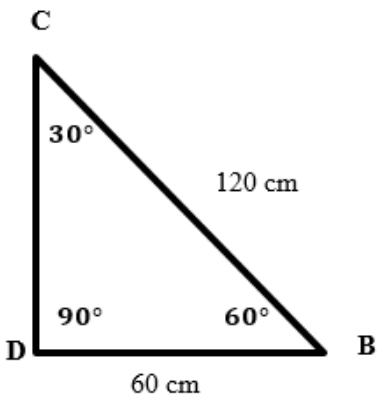

Berdasarkan rumus teorema Pythagoras untuk mencari panjang sisi $C D$ yang merupakan sisi tegak pertama menggunakan rumus $a^{2}=c^{2}-b^{2}$, maka perhitungannya adalah:

$\mathrm{CD}^{2}=\mathrm{CB}^{2}-\mathrm{BD}^{2}$

$C D=60 \sqrt{3}$

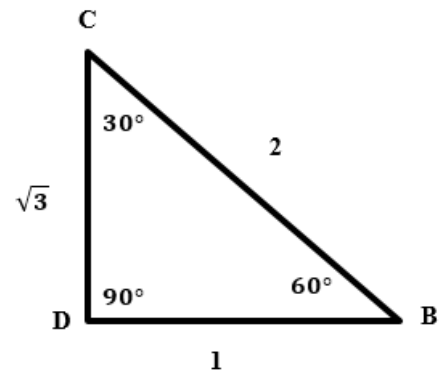

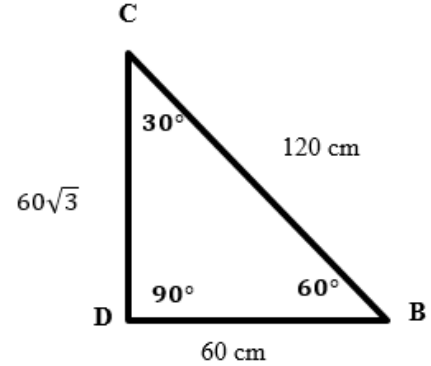

Mencari perbandingan

$\frac{B D}{C D}=\frac{60}{60 \sqrt{3}}=\frac{1}{\sqrt{3}}$

$\frac{B D}{B C}=\frac{60}{120}=\frac{1}{2}$

Maka didapatkan bahwa:

$B D: C D: B C=1: \sqrt{3}: 2$

Keterangan:

$B D$ adalah sisi depan sudut $30^{\circ}$

$C D$ adalah sisi depan sudut $60^{\circ}$

$B C$ adalah sisi depan sudut $90^{\circ}$

Maka di dapatkan perbandingan berikut:

Sisi di depan sudut ${ }^{\circ}:$ sisi di depan sudut $60^{\circ}:$ sisi miring $=1: \sqrt{3}: 2$.

\section{KESIMPULAN}

Pada atap rumah adat Baduy terdapat konsep teorema Pythagoras pada segitiga siku-siku. Pada motif batik Cikadu Pandeglang mengandung konsep pembuktian kebenaran teorema Pytagoras. Pada gapura khas Banten, menara pengintai Benteng Speelwijk, dan gapura Masjid Kasunyatan mengandung konsep aturan untuk menentukan jenis segitiga berdasarkan panjang sisi-sisi yang diketahui. Pada totopong Baduy mengandung konsep tripel Pythagoras. Pada alas menara Banten dan ulur tenun Baduy mengandung konsep perbandingan sisi-sisi pada segitiga siku-siku sama kaki. Pada totopong Baduy terdapat keteraturan konsep tripel Pythagoras. Pada atap masjid agung Banten dan leuit Baduy mengandung konsep perbandingan sisi-sisi pada segitiga siku-siku dengan sudut $30^{\circ}, 60^{\circ}$, dan $90^{\circ}$.

Dengan kajian terhadap budaya Banten yang ditinjau dari konsep teorema Pythagoras, dapat digunakan oleh guru dalam pembelajaran matematika pada materi teorema Pythagoras di sekolah, sehingga diharapkan siswa bukan hanya mencapai kompetensi pengetahuan terkait materi transformasi, tetapi juga sebagai bentuk penguatan pendidikan karakter pada nilai nasionalis dengan memiliki kompetensi sikap kecintaan terhadap budayanya sendiri dapat tumbuh dan dimiliki oleh siswa sebagai jati diri bangsa.

\section{REKOMENDASI}

Budaya Banten dalam penelitian ini belum seluruhnya dieksplor dalam kajian etnomatematika. Oleh sebab itu, peneliti menyarankan agar memberikan focus kepada budaya Banten lainnya. Konsep kajian budaya tidak hanya Pythagoras dan dapat juga pada kajian matematika lainnya. 


\section{UCAPAN TERIMAKASIH}

Peneliti mengucapkan terimakasih banyak kepada berbagai pihak yang telah turut membantu dalam penyusunan artikel ini, terutama dosen pembimbing dan dosen-dosen yang telah memberikan masukan serta saran yang membangun sehingga dapat terwujud sebuah artikel yang berkualitas baik.

\section{DAFTAR PUSTAKA}

Affaf, M. (2016). Konstruksi baru untuk tripel pythagoras. JP2M (Jurnal Pendidikan dan Pembelajaran Matematika), 2(1), 69-78. https://doi.org/10.29100/jp2m.v2i1.217

Agarwal, R. P. (2020). Pythagorean theorem before and after pythagoras. Advanced Studies in Contemporary Mathematics, 30(3), 357-389.

Akbar, P., Hamid, A., Bernard, M., \& Sugandi, A. I. (2017). Analisis kemampuan pemecahan masalah dan disposisi matematik siswa kelas xi sma putra juang dalam materi peluang. Jurnal Cendekia: Jurnal Pendidikan Matematika, 2(1), 144-153. https://doi.org/10.31004/cendekia.v2i1.62

Anggraheni, D. S., Attamimi, H., \& Jumardi. (2020). Perkembangan kerajaan islam di banten pada masa sultan ageng tirtayasa dalam aspek politik dan sosial. Jurnal Pemikiran Pendidikan dan Penelitian Kesejarahan, 7(2), 146-159. https://ojs.unm.ac.id/pattingalloang/article/view/13518

Cahyanindya, B. A., \& Mampouw, H. L. (2020). Pengembangan media puppy berbasis adobe flash cs6 untuk pembelajaran teorema pythagoras. Jurnal Cendekia: Jurnal Pendidikan Matematika, 4(1), 396-405. https://doi.org/10.31004/cendekia.v4i1.233

Heriawan, A., Soetrisnaadisendjaja, D., \& Hidayati, S. (2018). Kajian etnopaedagogi: seba dalam masyarakat baduy. Jurnal Hermeneutika, 4(2), 47-57. https://jurnal.untirta.ac.id/index.php/Hermeneutika

Iskandar, J., \& Iskandar, B. S. (2017). Kearifan ekologi orang baduy dalam konservasi padi dengan "sistem leuit". Jurnal Biodjati, 2(1), 38-51. https://doi.org/10.15575/biodjati.v2i1.1289

Khaerunnisa, E., Setiani, Y., \& Rafianti, I. (2018). Analisis keteraturan matematis pada budaya banten. Prima: Jurnal Pendidikan Matematika, 2(2), 81-91. http://dx.doi.org/10.31000/prima.v2i2.707

Laksmi, B. W. (2017). Masjid agung banten: perpaduan tiga budaya dalam satu arsitektur. Seminar Ikatan Peneliti Lingkungan Binaan Indonesia, A365-A368. https://doi.org/10.32315/sem.1.a365

Lestari, H., Pamungkas, A. S., \& Alamsyah, T. P. (2019). Pengembangan lembar kerja siswa eksploratif berkonteks budaya banten pada mata pelajaran matematika di sekolah dasar. Prisma Sains: Jurnal Pengkajian IImu dan Pembelajaran Matematika dan IPA IKIP Mataram, 7(1), 4859. https://doi.org/10.33394/j-ps.v0i0.1401

Maftukha, N. (2012). Sejarah visualisasi tenun baduy. International Seminar on Art History and Visual Culture in Southeast Asia, 1-20.

Maftukha, N., Yustiono, Y., \& Adriati, I. (2017). Visualisasi tenun baduy. Journal of Visual Art and Design, 9(2), 51-66. https://doi.org/10.5614/j.vad.2017.9.2.1

Megantari, A. A. P., \& Setyawan. (2019). Kajian tenun baduy di desa kanekes provinsi banten. Texture: Art \& Culture Journal, 2(2), 107-119. https://jurnal.isi-ska.ac.id/index.php/TXT/article/view/2783 
Nadya, A. (2017). Gaya arsitektur masjid kasunyatan, masjid tertua di banten. Seminar Ikatan Peneliti Lingkungan Binaan Indonesia, A311-A316. https://doi.org/10.32315/sem.1.a311

Naredi, H., Jumardi, Qodariah, L., \& Absor, N. F. (2020). Pembelajaran sejarah berbasis sejarah lokal banten dan kaitannya dengan toleransi beragama (studi kasus: masjid agung banten dan vihara $\begin{array}{lll}\text { avalokitesvara). Jurnal } & \text { Candrasangkala, }\end{array}$ http://jurnal.untirta.ac.id/index.php/Candrasangkala/article/view/8019

Noto, M. S., Firmasari, S., \& Fatchurrohman, M. (2018). Etnomatematika pada sumur purbakala desa kaliwadas cirebon dan kaitannya dengan pembelajaran matematika di sekolah. Jurnal Riset Pendidikan Matematika, 5(2), 201-210. https://doi.org/10.21831/jrpm.v5i2.15714

Nugroho, G. N., \& Riyanto, O. R. (2019). Mathematical critical thinking ability reviewed from selfefficacy in discovery learning. Eduma: Mathematics Education Learning and Teaching, 8(1), 2532. http://dx.doi.org/10.24235/eduma.v8i1.4593

Rahmawati, Y. (2020). Pendekatan matematika realistik bernuansa etnomatematika: rumah gadang minangkabau pada materi teorema pythagoras. Jurnal Azimut, Februari, 22-29. http://ojs.unitaspdg.ac.id/index.php/azimut/article/view/636

Saefullah, A. (2018). Masjid kasunyatan banten: tinjauan sejarah dan arsitektur. Jurnal Lektur Keagamaan, 16(1), 127-158. https://doi.org/10.31291/jlk.v16i1.486

Saepudin, A. (2019). Unsur sejarah dalam motif batik kreasi cikadu tanjung lesung pandeglang. Universitas Islam Negeri Sultan Maulana Hasanuddin Banten.

Sardjono, A. B., \& Nugroho, S. (2017). Menengok arsitektur permukiman masyarakat badui : arsitektur berkelanjutan dari halaman sendiri. Jurnal Teknik Sipil dan Perencanaan, 19(1), 57-64. https://doi.org/10.15294/jtsp.v19i1.9499

Sitohang, S. R., Elindra, R., \& Saleh, A. (2020). Efektivitas penggunaan model pembelajaran kontekstual terhadap kemampuan berpikir kreatif matematis siswa di smp negeri 9 padangsidimpun. Jurnal MathEdu (Mathematic Education Journal), 3(3), 110-120. http://journal.ipts.ac.id/index.php/MathEdu/article/view/1813

Susilowati, D., Budiarto, A. S., Rukayah, R. S., \& Dewi, P. (2020). Evolusi pada tatanan ruang rumah baduy (studi kasus rumah baduy dalam dan baduy luar). NALARs, 19(2), 131-138. https://doi.org/10.24853/nalars.19.2.131-138

Sutoto. (2017). Dinamika transformasi budaya belajar suku baduy. Jurnal Penelitian Pendidikan, 17(2), 138-148. https://doi.org/10.17509/jpp.v17i2.8249

Titasari, N., Hendriana, H., \& Setiawan, W. (2019). Meningkatkan kemampuan pemahaman dan motivasi belajar siswa smp dalam menyelesaikan masalah teorema pythagoras menggunakan problem based learning. Journal on Education, 01(03), 550-561. http://jonedu.org 